\title{
Recensión del Libro: \\ «Naturphilosophie» de Thomas Kirchhoff et al ${ }^{1}$
}

\author{
Francisco José Soler Gil \\ Universidad de Sevilla
}

Recibido: 8/10/2016 Aprobado: 15/10/2016

La filosofía de la naturaleza es la más antigua de las disciplinas filosóficas, al menos si nos limitamos a considerar la tradición del pensamiento occidental que nace con Tales de Mileto y sus sucesores Anaximandro y Anaxímenes.

No obstante, y a pesar de los muy honorables títulos que puede exhibir un campo de estudio del que han ido brotando las diversas ciencias naturales, lo cierto es que la filosofía de la naturaleza no termina de encontrar su sitio, sobre todo desde el inicio de la época moderna. En parte ello es debido a la problemática relación que mantiene con sus hijas, las ciencias, al menos desde el siglo XIX, o incluso ya desde el siglo XVIII. Pero en parte hay que buscar también la causa en los reiterados intentos de secuestrar la disciplina por parte de programas de investigación particulares (o incluso por parte de ideologías particulares).

${ }^{1}$ Thomas Kirchhoff et al. (2017), Naturphilosophie, Tübingen, Mohr Siebeck - utb. 368 páginas. 
El último de tales intentos de secuestro, que aún no ha sido realmente superado, lo viene sufriendo la filosofía de la naturaleza por parte del pensamiento materialista, y sobre todo su variante denominada «naturalista», que pretende instalar a las ciencias naturales como definidoras últimas de todo lo real. De manera que aún resulta frecuente encontrar el naturalismo filosófico amalgamado en las presentaciones de los diversos temas de filosofía de la naturaleza, e incluso en los manuales introductorios de esta disciplina, como si fuera un componente inseparable de la misma.

En las mencionadas circunstancias, resulta por eso muy oportuna, y digna de celebrar, la minuciosa panorámica de la filosofía de la naturaleza, de sus temas, su historia, sus posibles enfoques alternativos y sus conexiones con otras disciplinas, tanto teóricas como prácticas, que Thomas Kirchhoff y una treintena de especialistas alemanes nos ofrecen ahora con el libro «Naturphilosophie», publicado en 2017 en la prestigiosa editorial Mohr Siebeck, ahora englobada en el grupo UTB.

Pues el primer, y quizás más notorio rasgo que se descubre en la lectura de esta obra es el esfuerzo por tratar - si bien a nivel introductorio - todos los asuntos relacionados de alguna manera con la filosofía de la naturaleza, y desde el mayor número posible de ángulos y planteamientos.

Para lograr este ambicioso objetivo, el libro aparece dividido en cuatro grandes secciones (que engloban un total de treinta y siete subsecciones, además de la introducción y los habituales índices y breves notas biográficas):

(I) Historia y sistemática; (II) conceptos fundamentales de la filosofía de la naturaleza; (III) relaciones con la naturaleza; (IV) filosofía de la naturaleza en la práctica. 
Las nueve subsecciones en que se divide la primera parte, enfocan ante todo momentos particulares de especial relevancia para el desarrollo de la filosofía de la naturaleza, como son las discusiones en torno al primer principio de la realidad en Grecia, o los desarrollos del concepto del cosmos como creación en el pensamiento medieval, o también la controversia acerca de la infinitud o infinitud del universo a comienzos de la Edad Moderna. Es inevitable en un libro panorámico el dejar fuera muchos detalles de una historia que, en el caso de esta disciplina, abarca un periodo de más de dos mil quinientos años. Pero uno de los méritos de la obra de Kirchhoff et al. es salvar en esa criba episodios como el del enfrentamiento entre representantes de las ciencias naturales tales como Helmholtz y los promotores de la filosofía de la naturaleza del romanticismo filosófico decimonónico, así como los diversos intentos postrománticos de reformular la disciplina y situarla en una cierta relación con respecto a dichas ciencias. Gracias a ello, el lector puede ya hacerse, desde el primer momento, una idea clara del carácter abierto y controvertido del campo que se pretende cartografiar en esta obra. Tras una exposición de las distintas vías que hoy se exploran como aspectos o formas de la filosofía de la naturaleza, la primera parte concluye con una oportuna reflexión acerca de hasta qué punto cabe delimitar este campo como una «única» disciplina, y no más bien como un conjunto de aproximaciones a la naturaleza que dependen de los modos posibles de relacionarse con ella que se tratarán en la tercera parte de la obra.

Las diez subsecciones (más una subsección introductoria) que componen la segunda parte, están dedicadas a esbozar una serie de conceptos claves que se manejan y discuten en la filosofía de la naturaleza. En cierto sentido cabe 
considerar a esta como la parte más convencional de la obra, no por el análisis de los conceptos ofrecido - que es de gran calidad - sino por el mero hecho de que se trata de una parte que en ningún buen manual de filosofía de la naturaleza puede faltar. Pero incluso en esta sección del libro se hace notar el impulso a abrir el campo de exploración más allá de lo que se encuentra usualmente en la bibliografía actual. $\mathrm{Y}$ así, junto a las (sin duda interesantes) subsecciones dedicadas a los conceptos de «cosmos y mundo», «espacio y tiempo», «materia, fuerza, energía», «vida», etc., encontramos también subsecciones tales como, «creación», que enfoca la frontera entre la filosofía de la naturaleza y la teología natural, y «paisaje», que plantea puntos de contacto con la geografía, la estética, e incluso el derecho.

Con todo, seguramente la parte más inusual de la obra la constituye la tercera sección, que se ocupa de esbozar diversas formas de relación entre el hombre y la naturaleza. En la introducción de esta parte se explica el objetivo de la misma así:

Con ello se desarrolla un enfoque decididamente relacional de la naturaleza. Debe así superarse la reducción a cosificaciones, a un hablar de la naturaleza meramente fijado en los objetos. En lugar de ello se trata de explorar que clases de relación dirigen la experiencia y la investigación de la naturaleza, posibilitando el conocimiento y el dominio, o bien poniéndolos al descubierto como problemáticos... (Kirchhoff et al, 2017: 173)

Constelaciones de relaciones corporales, estéticas, teóricas, experimentales, narrativas, religiosas etc. son exploradas en las subsecciones que componen esta parte, y que, ciertamente, desborda con mucho los límites del 
terreno que comúnmente se está dispuesto a conceder a la filosofía de la naturaleza.

Por último, la obra incluye una sección cuarta dedicada a los aspectos filosóficos de cuestiones tan prácticas y actualmente disputadas como las técnicas de manipulación genética, el papel de la naturaleza en la educación, las tendencias de «regreso a la naturaleza», la ética animal etc.

Evidentemente, dada la amplitud de su temática, y el numeroso grupo de autores que tiene que encargarse por ello de desarrollarla, el libro de Kirchhoff et al. no deja de presentar diferencias de estilo entre unas subsecciones y otras, ciertos altibajos estilísticos y cualitativos, y en ocasiones repeticiones temáticas (aunque por lo general desde perspectivas diferentes, cuando esto ocurre). Pero todo esto, que resulta inevitable en una obra así, no empaña las virtudes, mucho mayores, que posee.

Considerado en conjunto, este compendio de temas y discusiones de filosofía de la naturaleza constituye todo un instrumento de terapia mental frente a los enfoques excesivamente reduccionistas que han predominado en la filosofía de la naturaleza de los últimos decenios.

Sólo por eso ya merece una encendida recomendación.

Francisco Soler Gil soler@unibremen.de 
